\title{
Disease Activity, Smoking, and Reproductive-related Predictors of Poor Prognosis in Patients with Very Early Inflammatory Polyarthritis
}

\author{
SUZANNE M.M. VERSTAPPEN, MELANIE J. McCOY, CHRIS ROBERTS, NICOLA E. DALE, \\ ANDREW B. HASSELL, DEBORAH P.M. SYMMONS; and the Steroids In Very Early Arthritis Investigators
}

\begin{abstract}
Objective. To identify disease activity, smoking, and reproductive-related predictors of a poor prognosis in patients with very early inflammatory polyarthritis (IP).

Methods. Patients with very early IP (symptom duration 4-11 weeks) included in our study were participants in the STIVEA (Steroids In Very Early Arthritis) randomized placebo-controlled trial. At baseline, disease-related variables were measured and patients were asked to complete a questionnaire covering smoking status and reproductive questions. Baseline predictors of poor prognosis [i.e., the need to start disease-modifying antirheumatic drug (DMARD) therapy by 6 months or the clinical diagnosis of rheumatoid arthritis (RA) at 12 months] were identified, applying logistic regression analyses adjusted for treatment group.

Results. Rheumatoid factor (RF) positivity was one of the strongest clinical predictors of a poor prognosis: OR for DMARD therapy at 6 months, 4.00 (95\% CI 2.00-8.00) and OR for a diagnosis of RA at 12 months, 9.48 (95\% CI 4.48-20.07). There was a significant association between current smoking at baseline compared to never smoking and a diagnosis of RA at 12 months (OR 3.15, 95\% CI 1.16-8.56).

Conclusion. About 6 in 7 patients with very early RF-positive IP were diagnosed with RA 1 year later. In addition, 1 in 4 IP patients who smoke will develop RA later. It is recommended to treat RF-positive patients who have IP with DMARD at presentation and to advise patients to stop smoking. (First Release Dec 1 2010; J Rheumatol 2011;38:429-33; doi:10.3899/jrheum.100756)
\end{abstract}

\section{Key Indexing Terms: \\ EARLY INFLAMMATORY POLYARTHRITIS RHEUMATOID ARTHRITIS DISEASE-MODIFYING ANTIRHEUMATIC DRUG}

\author{
POOR PROGNOSIS \\ DISEASE ACTIVITY \\ LIFESTYLE FACTORS
}

Rheumatoid arthritis (RA) is the most common form of inflammatory polyarthritis (IP). Evidence from the Norfolk Arthritis Register suggests that at least half of those who develop IP lasting at least 4 weeks go on to develop chron-

From the Arthritis Research UK Epidemiology Unit, and the Department of Biostatistics, Manchester Academic Health Sciences Centre, the University of Manchester, Manchester; and the University Hospital of North Staffordshire, Stoke-on-Trent, United Kingdom.

Supported by Arthritis Research UK; and by Pfizer Ltd.

S.M.M. Verstappen, MSc, PhD, Arthritis Research UK Epidemiology Unit, Manchester Academic Health Sciences Centre, University of Manchester; M.J. McCoy, BSc, Arthritis Research UK Epidemiology Unit, Manchester Academic Health Sciences Centre, University of Manchester; C. Roberts, MSc, PhD, Department of Biostatistics, Manchester Academic Health Sciences Centre, University of Manchester; N.E. Dale, MA, Arthritis Research UK Epidemiology Unit, Manchester Academic Health Sciences Centre, University of Manchester; A.B. Hassell, MD, MMedEd, FRCP, University Hospital of North Staffordshire; D.P.M. Symmons, MD, FFPH, FRCP, Arthritis Research UK Epidemiology Unit, Manchester Professor, Academic Health Sciences Centre, University of Manchester.

Address correspondence to Prof. D.P.M. Symmons, Arthritis

Research UK Epidemiology Unit, Stopford Building, The University of Manchester, Manchester M13 9PT, United Kingdom.

E-mail: deborah.symmons@manchester.ac.uk

Accepted for publication October 14, 2010. ic $\mathrm{RA}^{1}$. The course of this inflammatory autoimmune disease varies considerably from a mild variant to a severe chronic disabling condition 2,3 . Rheumatoid factor (RF) is probably the most consistent predictor for a poor prognosis, as measured by radiographic damage, functional disability, and premature mortality $4,5,6,7$.

Although the etiology of RA is not fully understood, it is almost certainly due to a combination of genetic and unknown environmental factors. Nongenetic causes, such as lifestyle factors, may explain up to $33 \%$ of the risk of developing $\mathrm{RA}^{8}$. Cigarette smoking has consistently been found to be associated with the development of IP and RA ${ }^{9,10}$.

The higher incidence of RA in women may suggest a hormonal influence. An overview of 18 studies showed that in most, although not all, the use of the oral contraceptive pill (OCP), either current or ever, had a protective effect for RA of sufficient severity to merit hospital referral ${ }^{8}$.

To define modifiable predictors of poor prognosis in patients with IP or with very early RA, it is important to collect data on possible predictors near the time of disease onset. In the Steroids In Very Early Arthritis (STIVEA) multicenter double-blind placebo-controlled randomized trial, Personal non-commercial use only. The Journal of Rheumatology Copyright (c) 2011. All rights reserved. 
investigating the effect of a 3-week course of intramuscular methylprednisolone injections, patients were seen within 11 weeks of symptom onset ${ }^{11}$. We aimed to identify clinical, demographic, smoking, and reproductive-related predictors of a poor prognosis (after controlling for treatment arm) in patients with very early IP included in the STIVEA trial ${ }^{11}$.

\section{MATERIALS AND METHODS}

General practitioners were asked to refer patients with very early IP (4-11 weeks' symptom duration) to the rheumatologist. Patients were randomized to receive 3 intramuscular injections of either methylprednisolone or placebo (N-saline) at 1-week intervals and were followed for 12 months. For our study, the 2 groups were combined and treated as 1 study population. Since we found a beneficial effect of treatment in the main trial, all results were adjusted for treatment group in this study ${ }^{11}$. The North West Research Ethics Committee UK approved the study and all patients gave written informed consent.

Poor prognosis. In this study, 2 definitions for a poor prognosis were used. The first definition was the need to start disease-modifying antirheumatic drugs (DMARD) by the 6-months assessment, i.e., the referral of the patient to the rheumatologist by the research nurse to consider DMARD, according to the following criteria: 3 or more swollen joints, 6 or more tender joints, at least 45 minutes of early morning stiffness, or erythrocyte sedimentation rate $(E S R) \geq 28 \mathrm{~mm} / \mathrm{h}$, or the actual start of DMARD (including oral corticosteroids) ${ }^{11}$. The second definition of a poor prognosis was a diagnosis of RA determined by the rheumatologist at 12 months after inclusion into the study.

Disease and demographic characteristics. The following demographic and disease-related factors were collected at baseline: age; sex; symptom duration ( $\geq 8$ weeks vs $<8$ weeks, i.e., median cutoff); the 3 -component 28 -joint Disease Activity Score (DAS28), calculated from the 28 tender joint count, 28 swollen joint count, and ESR; patients' assessment on visual analog scales (VAS) for pain and fatigue; VAS disease activity noted by the rheumatologist; rheumatoid factor (RF; positive if $>40 \mu \mathrm{l}$ ); functional disability [British version of Health Assessment Questionnaire (HAQ), 0-3,

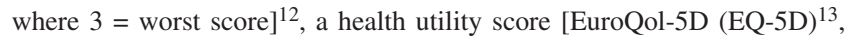
-0.59 to 1 , where $1=$ best health status]; and the Medical Outcomes Study Short-Form 36 (SF-36) physical component score (PCS) and mental component score (MCS), completed by the patient $(0-100$ scale, where $100=$ better health) ${ }^{14,15}$.

Smoking and reproductive factors. Patients were asked to complete a questionnaire at baseline that covered smoking status (current smoker, ex-smoker, and never smoked) and women were also asked about reproductive factors, hormone replacement therapy, and the use of the OCP. The lifestyle questionnaire was completed by a subgroup of the total study population because some centers did not send out the questionnaire.

Statistical analyses. Multiple logistic regression analysis was applied to explore whether baseline characteristics were different between patients who completed the lifestyle questionnaire and those who did not. The association between baseline factors and the need to start DMARD by the 6-month visit or between baseline factors and a diagnosis of RA by the physician at 12 months was evaluated using logistic regression analysis in patients with complete data at those timepoints. OR with 95\% CI were adjusted for trial treatment group. In subsequent analysis, OR were adjusted for trial treatment group, age, and sex. All statistical analyses were conducted using Stata v. 9 (StataCorp, College Station, TX, USA).

\section{RESULTS}

Baseline characteristics. At 6 months, 68\% (173/253) of the total study population with available data had either started or had been referred to start DMARD. In the group of patients who completed a lifestyle questionnaire, this percentage was $66.1 \%(107 / 162)$. At 12 months, $55 \%$ of the total study population (121/222 patients with data available about diagnosis) and $58 \%$ of the patients who completed a baseline lifestyle questionnaire (86/149 patients with data available about diagnosis) had a physician diagnosis of RA. The baseline characteristics of all 4 groups are shown in Table 1. Mean age at baseline was 56 years (SD 15). Sixty-nine percent of the patients were women and 33\% were RF-positive at baseline. Disease activity and demographic characteristics did not differ among those patients who did and those who did not fill in a questionnaire at baseline.

In the group of patients who completed a questionnaire and for whom 6-month followup data were available, 60 $(37.2 \%)$ were ex-smokers who stopped smoking on average 17 years before our study. Eighty-five women had given birth to a total of 196 children, including 2 sets of twins. On average, the last baby was born 25 years before baseline visit.

In the group of patients who filled in a questionnaire and for whom 12-month followup diagnosis data were available $(\mathrm{n}=148), 59$ (39.9\%) were ex-smokers who stopped smoking on average 17 years before this study. Seventy-six women had given birth to a total of 172 children, including 2 sets of twins; on average the last births were 26 years before the baseline visit.

Possible predictors for a poor prognosis. None of the demographic characteristics was associated with the need to start DMARD at 6 months or with a diagnosis of RA at 12 months (Table 2). However, a trend toward an association between increased disease duration $(\geq 8$ weeks vs $<8$ weeks) and the diagnosis of RA was observed (OR 1.61, 95\% CI 0.94-2.75). RF positivity was one of the strongest clinical predictors of a poor prognosis: OR for DMARD therapy at 6 months was 4.00 (95\% CI 2.00-8.00), and OR for a diagnosis of RA at 12 months was 9.48 (95\% CI 4.48-20.07). Worse disease activity at baseline, including a higher DAS28 score and more pain and fatigue on VAS, was associated with the need to start DMARD by 6 months and with a diagnosis of RA at 12 months. Patients with worse functional ability and poorer quality of life were also more likely to need DMARD by 6 months and to be diagnosed with RA at 12 months. A lower score on the SF-36 physical component score was associated with the need to start DMARD by 6 months.

There was a significant association between current smoking compared to never smoking at baseline and a diagnosis of RA at 12 months (OR 3.15, 95\% CI 1.16-8.56; Table 3 ). In addition, there was a trend toward an increased risk for the need to start DMARD by 6 months in patients who smoked in the past versus patients who never smoked (OR 2.12, 95\% CI 0.98-4.61).

In women, OCP use, previous pregnancies, hormone replacement therapy, and hysterectomy were not associated 
Table 1. Baseline characteristics separately for the total study population and for patients who filled in the lifestyle questionnaire. Values are mean (SD) or median (interquartile range), unless otherwise specified.

\begin{tabular}{|c|c|c|c|c|}
\hline \multirow[b]{2}{*}{ Characteristic } & \multicolumn{2}{|c|}{ DMARD Outcome } & \multicolumn{2}{|c|}{ RA Outcome } \\
\hline & $\begin{array}{l}\text { Total population, } \\
\quad \mathrm{n}=253\end{array}$ & $\begin{array}{l}\text { Patients who Completed } \\
\text { the Questionnaire, } \\
n=162\end{array}$ & $\begin{array}{l}\text { Total Population, } \\
\quad \mathrm{n}=222\end{array}$ & $\begin{array}{l}\text { Patients who Completed } \\
\text { the Questionnaire, } \\
n=149\end{array}$ \\
\hline Age, yrs & $56(15)$ & $55(15)$ & $56(15)$ & $56(14)$ \\
\hline Sex (\% women) & $173 / 253(68)$ & 114/162 (70) & $152 / 222(68)$ & 103/149 (69) \\
\hline Symptom duration, wks & $8(6-0)$ & $8(6-10)$ & $8(6-10)$ & $8(6-10)$ \\
\hline VAS fatigue, mm & $53(26)$ & $54(25)$ & $54(26)$ & $55(25)$ \\
\hline VAS physician, mm & $47(20)$ & $48(20)$ & $48(20)$ & $49(21)$ \\
\hline RF-positive (\%) & $81 / 247(32.8)$ & $52 / 158(33)$ & $71 / 219(32.4)$ & $48 / 146(33)$ \\
\hline HAQ score & $1.1(0.6-1.6)$ & $1.1(0.6-1.6)$ & $1.3(0.6-1.6)$ & $1.2(0.6-1.6)$ \\
\hline SF-36 PCS score & $39(7)$ & $39(7)$ & $39(7)$ & $39(7)$ \\
\hline SF-36 MCS score & $44(6)$ & $44(7)$ & $44(7)$ & $45(6)$ \\
\hline
\end{tabular}

DAS28: 28-joint Disease Activity Score (maximum score = 10); VAS: visual analog scale (range 0-100 mm = worst score); HAQ: Health Assessment Questionnaire (range 0-3 = worst functional ability); EQ-5D: EuroQol-5D dimension utility score (range 1 to $-0.59=$ worst health); SF-36: Medical Outcomes Study Short-Form 36; MCS: SF-36 mental component summary score; PCS: SF-36 physical component summary score; RF: rheumatoid factor; DMARD: disease-modifying antirheumatic drug; RA: rheumatoid arthritis.

Table 2. Baseline demographic and disease-related risk factors for the need to start DMARD therapy by 6 months and the diagnosis of RA at 12 months.

\begin{tabular}{|c|c|c|c|c|c|c|c|c|c|c|}
\hline \multirow{2}{*}{$\begin{array}{l}\text { Demographic and } \\
\text { Disease-related } \\
\text { Risk Factors }\end{array}$} & \multirow[b]{2}{*}{$\mathrm{n}$} & \multicolumn{4}{|c|}{ DMARD Outcome } & \multicolumn{5}{|c|}{ RA Outcome } \\
\hline & & $\begin{array}{l}\text { Trial Treatment- } \\
\text { adjusted OR } \\
(95 \% \text { CI) }\end{array}$ & $\mathrm{p}$ & $\begin{array}{l}\text { OR Adjusted for } \\
\text { Trial Treatment, } \\
\text { Age, and Sex } \\
(95 \% \mathrm{CI})\end{array}$ & $\mathrm{p}$ & $\mathrm{n}$ & $\begin{array}{l}\text { Trial Treatment- } \\
\text { adjusted OR } \\
(95 \% \text { CI })\end{array}$ & $\mathrm{p}$ & $\begin{array}{l}\text { OR Adjusted for } \\
\text { Trial Treatment, } \\
\text { Age, and Sex } \\
\quad(95 \% \mathrm{CI})\end{array}$ & $\mathrm{p}$ \\
\hline Age, yrs & 253 & $1.01(0.99-1.02)$ & 0.543 & & & 222 & $1.01(0.99-1.03)$ & 0.420 & & \\
\hline Sex, women & 253 & $0.68(0.37-1.23)$ & 0.205 & & & 222 & $1.00(0.57-1.78)$ & 0.992 & & \\
\hline Disease duration, wks & 253 & $1.12(0.66-1.93)$ & 0.672 & $1.15(0.67-1.98)$ & 0.613 & 222 & $1.61(0.94-2.75)$ & 0.085 & $1.60(0.93-2.76)$ & 0.089 \\
\hline DAS28 (3) & 247 & $1.54(1.20-1.97)$ & 0.001 & $1.58(1.22-2.04)$ & $<0.001$ & 219 & $1.44(1.12-1.84)$ & 0.004 & $1.43(1.11-1.84)$ & 0.005 \\
\hline VAS pain, per mm & 243 & $1.02(1.01-1.03)$ & 0.001 & $1.02(1.01-1.03)$ & 0.001 & 214 & $1.01(1.00-1.03)$ & 0.013 & $1.01(1.00-1.03)$ & 0.012 \\
\hline VAS fatigue, per mm & 243 & $1.01(1.00-1.02)$ & 0.013 & $1.02(1.00-1.03)$ & 0.005 & 214 & $1.01(1.00-1.02)$ & 0.039 & $1.01(1.00-1.02)$ & 0.022 \\
\hline VAS physician, per mm & 251 & $1.02(1.00-1.03)$ & 0.015 & $1.02(1.00-1.03)$ & 0.013 & 220 & $1.02(1.01-1.04)$ & 0.002 & $1.02(1.01-1.04)$ & 0.002 \\
\hline RF-positive & 247 & $4.00(2.00-8.00)$ & $<0.001$ & $4.31(2.14-8.70)$ & $<0.001$ & 219 & $9.48(4.48-20.07)$ & $<0.001$ & $10.33(4.80-22.23)$ & $<0.001$ \\
\hline HAQ score & 244 & $2.19(1.42-3.39)$ & $<0.001$ & $2.31(1.49-3.60)$ & $<0.001$ & 215 & $1.82(1.21-2.74)$ & 0.004 & $1.83(1.20-2.78)$ & 0.005 \\
\hline SF-36 PCS score & 234 & $0.94(0.90-0.98)$ & 0.003 & $0.93(0.89-0.98)$ & 0.002 & 206 & $0.98(0.94-1.02)$ & 0.246 & $0.98(0.94-1.02)$ & 0.265 \\
\hline SF-36 MCS score & 234 & $1.04(0.90-1.08)$ & 0.133 & $1.03(0.99-1.08)$ & 0.147 & 206 & $1.01(0.96-1.05)$ & 0.763 & $1.00(0.96-1.05)$ & 0.854 \\
\hline EQ-5D utility score & 237 & $0.15(0.05-0.44)$ & 0.001 & $0.14(0.05-0.41)$ & $<0.001$ & 210 & $0.32(0.13-0.81)$ & 0.017 & $0.32(0.12-0.81)$ & 0.016 \\
\hline
\end{tabular}

n: number of patients with available data. DMARD: disease-modifying antirheumatic drug; DAS28 (3): 28-joint count Disease Activity Score; VAS: visual analog scale; RF: rheumatoid factor; HAQ: Health Assessment Questionnaire; SF-36: Medical Outcomes Study Short-Form 36; PCS: SF-36 physical component summary score; MCS: SF-36 mental component summary score; EQ-5D: EuroQol-5D dimension utility score; RA: rheumatoid arthritis.

with a poor prognosis (Table 3). Patients who were still menstruating were less likely to need DMARD by 6 months (OR 0.38, 95\% CI 0.16-0.94). The association persisted after adjustment for age but was no longer significant (OR $0.27,95 \%$ CI $0.06-1.30$ ).

\section{DISCUSSION}

In our study of patients with very early IP, we found that RF positivity was one of the strongest predictors for a poor prognosis. It must be noted, however, that the percentage of patients who were RF-positive at baseline was very low, and thus the 95\% CI interval was very wide. Our result is in agreement with other studies in which RF was a strong predictor for poor outcome measures such as worse functional disability, joint damage, and the development of $\mathrm{RA}^{2,4,5,6,7}$. However, none of those studies examined the association among demographic characteristics, disease activity, and functional disability and the need for DMARD in patients with very early IP. In one study, using data from 2 early arthritis cohorts (the Leiden Early Arthritis Clinic and the British Early Rheumatoid Arthritis Study), investigating the association between baseline disease activity characteristics 
Table 3. Smoking and reproductive-related risk factors for the need to start DMARD therapy by 6 months and the diagnosis of RA at 12 months.

\begin{tabular}{|c|c|c|c|c|c|c|c|c|c|c|}
\hline \multirow[b]{2}{*}{ Risk Factors } & \multirow[b]{2}{*}{$\mathrm{n} / \mathrm{N}$} & \multicolumn{3}{|c|}{ DMARD Outcome } & \multicolumn{6}{|c|}{ RA Outcome } \\
\hline & & $\begin{array}{l}\text { Trial Treatment- } \\
\text { adjusted OR } \\
(95 \% \mathrm{CI})\end{array}$ & $\mathrm{p}$ & $\begin{array}{l}\text { OR Adjusted for } \\
\text { Trial Treatment, } \\
\text { Age, and Sex } \\
(95 \% \mathrm{CI})\end{array}$ & $\mathrm{p}$ & $\mathrm{n} / \mathrm{N}$ & $\begin{array}{l}\text { Trial Treatment- } \\
\text { adjusted OR } \\
(95 \% \mathrm{CI})\end{array}$ & $\mathrm{p}$ & $\begin{array}{l}\text { OR Adjusted for } \\
\text { Trial Treatment, } \\
\text { Age, and Sex } \\
(95 \% \mathrm{CI})\end{array}$ & $\mathrm{p}$ \\
\hline \multicolumn{11}{|l|}{ Smoking } \\
\hline Never & $65 / 161$ & Reference & & Reference & & $61 / 148$ & Reference & & Reference & \\
\hline Still menstruating & $35 / 103$ & $0.38(0.16-0.94)$ & 0.036 & $0.27(0.06-1.30)$ & 0.103 & $30 / 92$ & $0.57(0.23-1.44)$ & 0.234 & $0.49(0.10-2.41)$ & 0.382 \\
\hline OCP use & $67 / 105$ & $1.17(0.49-2.79)$ & 0.727 & $1.69(0.61-4.64)$ & 0.311 & $63 / 95$ & $1.67(0.68-4.10)$ & 0.260 & $2.71(0.89-8.24)$ & 0.078 \\
\hline Been pregnant & $86 / 107$ & $0.91(0.30-2.78)$ & 0.867 & $0.78(0.25-2.47)$ & 0.670 & $77 / 96$ & $2.00(0.66-6.12)$ & 0.223 & $1.91(0.62-5.92)$ & 0.262 \\
\hline Had any children & $85 / 105$ & $0.51(0.15-1.75)$ & 0.286 & $0.46(0.13-1.63)$ & 0.228 & $76 / 96$ & $1.63(0.56-4.80)$ & 0.372 & $1.54(0.51-4.63)$ & 0.442 \\
\hline Stillbirths & $5 / 102$ & $0.30(0.04-2.04)$ & 0.219 & $0.27(0.04-1.81)$ & 0.176 & $4 / 91$ & $0.19(0.02-2.08)$ & 0.175 & $0.17(0.02-1.89)$ & 0.150 \\
\hline Miscarriages & $21 / 100$ & $0.55(0.20-1.49)$ & 0.241 & $0.56(0.20-1.53)$ & 0.256 & $18 / 90$ & $1.22(0.41-3.62)$ & 0.718 & $1.25(0.42-3.73)$ & 0.685 \\
\hline
\end{tabular}

$\mathrm{n} / \mathrm{N}$ : number of patients fulfilling criteria for each specific item/number of patients with available data. DMARD: disease-modifying antirheumatic drug; RA: rheumatoid arthritis; OCP: oral contraceptive pill; HRT: hormone replacement therapy.

and DMARD-free remission, an association between RF negativity and remission was observed ${ }^{16}$.

Other disease-related baseline factors associated with a poor prognosis in our study included a high DAS28 score, more fatigue and pain on self-reported VAS scores, worse functional disability, and lower quality of life (EQ-5D). Some of these factors have previously been associated with a diagnosis of RA in very early arthritis cohorts, but results are not very consistent. The purpose of our study was also to try to link these factors with the need for DMARD at 6 months. Interestingly, both worse functional disability and poorer quality of life, factors not included in the predefined criteria to refer patients to the rheumatologist to assess the need for DMARD, were associated with a need for DMARD by 6 months.

It is important to distinguish between risk factors for the onset of IP and risk factors for the persistence of IP once it is present. In our study we investigated the latter. Smoking is now one of the best-established environmental risk factors for the development of $\mathrm{RA}^{9,10,17}$. In particular, smoking is associated with RF-positive RA. The effect of smoking on the development of RA may also differ between men and women, with an increased risk in men in some studies ${ }^{18}$ but not in others ${ }^{17}$. These studies combine the investigation of onset and early outcome, while we have investigated persistence, given onset. In general, our results are in agreement with other studies in finding an association between current smoking and a diagnosis of RA at 12 months. Interestingly, we also found a trend toward an association between past smoking, but not current smoking, and the need to start DMARD by 6 months.

The higher incidence of RA in women compared to men may partly be caused by differences in hormonal factors. We found that women who were still menstruating were less likely to progress to RA. However, after adjustment for age, this association was no longer significant. In contrast to other studies $^{8}$, we did not find a protective effect of OCP use ever in our study population or any other association between measured reproductive hormonal factors and a poor prognosis.

Several methodological issues need to be considered when interpreting our results, especially the findings based on the questionnaire. The group of patients who filled in a lifestyle questionnaire was relatively small and the study may have been underpowered. The definition of poor prognosis as the need to start DMARD by 6 months or a diagnosis of RA at 12 months was chosen because these were the 2 outcome measures also used in the main report of the STIVEA trial ${ }^{11}$. A diagnosis of RA was made by the rheumatologist and was not based on fulfilling the 1987 American College of Rheumatology (ACR) criteria for RA. We deliberately did not apply the 1987 ACR criteria for RA because, in contrast to most studies in which RA as outcome measure is based on the 1987 ACR criteria, patients entered in this study were patients with very early IP, even taking the 12-months followup into account.

Among patients with very early IP, a positive RF is the strongest predictor for a poor prognosis later in the disease course. We also confirmed previous findings of an association between current smoking and the development of RA in this small study population.

\section{ACKNOWLEDGMENT}

The authors thank the rheumatologists and research nurses of the participating hospitals and general practitioners who referred patients to the rheumatology departments. We also thank members of the Trial Steering Committee of this study. 


\section{APPENDIX}

The STIVEA collaborators: Cannock Chase Hospital, Cannock, Dr. Diarmuid Mulherin; Haywood Hospital, Stoke-on-Trent, Dr. P.T. Dawes; Kings College Hospital, London, Prof. David Scott; Macclesfield District General Hospital, Dr. Susan Knight; Royal Cornwall Hospital, Truro, Dr. Martin Davis; Stepping Hill Hospital, Stockport, Dr. Jeff Marks; Manchester Royal Infirmary, Manchester, Dr. Ian Bruce; Russells Hall Hospital, Dudley, Prof. George Kitas; Hope Hospital, Salford, Dr. Terry O'Neill; Royal Lancaster Infirmary, Lancaster, Dr. Marwan Bukhari; Norfolk \& Norwich University Hospital, Norwich, Dr. Karl Gaffney; City Hospital Birmingham, Birmingham, Dr. Karim Raza; Freeman Hospital, Newcastle, Dr. Lesley Kay; Queen Elizabeth Hospital, Gateshead, Dr. Clive Kelly and Dr. Vadivelu Saravanan; Nevill Hall Hospital, Abergavenny, Dr. Stuart Linton; Taunton \& Somerset Hospital, Taunton, Dr. Cathy Laversuch; St. Helen's Hospital, St. Helens, Dr. Rikki Abernethy; Harold Wood Hospital, Romford, Prof. Kuntal Chakravarty; Poole General Hospital, Poole, Dr. Selwyn Richards; St. Georges Hospital, Tooting, Dr. Brian Bourke; The Queen Elizabeth The Queen Mother Hospital, Margate, Dr. Alison Leak; East Surrey Hospital, Redhill, Dr. Raad Makadsi; Ysbyty Gwynedd, Bangor, Prof. Peter Maddison.

\section{REFERENCES}

1. Symmons DP, Barrett EM, Bankhead CR, Scott DG, Silman AJ. The incidence of rheumatoid arthritis in the United Kingdom: results from the Norfolk Arthritis Register. Br J Rheumatol 1994;33:735-9.

2. Machold KP, Stamm TA, Eberl GJ, Nell VK, Dunky A, Uffmann $\mathrm{M}$, et al. Very recent onset arthritis - clinical, laboratory, and radiological findings during the first year of disease. J Rheumatol 2002;29:2278-87.

3. van Aken J, van Dongen H, le Cessie S, Allaart CF, Breedveld FC, Huizinga TW. Comparison of long term outcome of patients with rheumatoid arthritis presenting with undifferentiated arthritis or with rheumatoid arthritis: an observational cohort study. Ann Rheum Dis 2006;65:20-5.

4. Bukhari M, Lunt M, Harrison BJ, Scott DG, Symmons DP, Silman AJ. Rheumatoid factor is the major predictor of increasing severity of radiographic erosions in rheumatoid arthritis: results from the Norfolk Arthritis Register Study, a large inception cohort. Arthritis Rheum 2002;46:906-12.

5. van Zeben D, Hazes JM, Zwinderman AH, Vandenbroucke JP, Breedveld FC. Factors predicting outcome of rheumatoid arthritis: results of a followup study. J Rheumatol 1993;20:1288-96.

6. Vittecoq O, Pouplin S, Krzanowska K, Jouen-Beades F, Menard JF, Gayet A, et al. Rheumatoid factor is the strongest predictor of radiological progression of rheumatoid arthritis in a three-year prospective study in community-recruited patients. Rheumatology 2003;42:939-46.

7. Gonzalez A, Icen M, Kremers HM, Crowson CS, Davis JM III, Therneau TM, et al. Mortality trends in rheumatoid arthritis: the role of rheumatoid factor. J Rheumatol 2008;35:1009-14.

8. Oliver JE, Silman AJ. Risk factors for the development of rheumatoid arthritis. Scand J Rheumatol 2006;35:169-74.

9. Symmons DP, Bankhead CR, Harrison BJ, Brennan P, Barrett EM, Scott DG, et al. Blood transfusion, smoking, and obesity as risk factors for the development of rheumatoid arthritis: results from a primary care-based incident case-control study in Norfolk, England. Arthritis Rheum 1997;40:1955-61.

10. Harrison BJ. Influence of cigarette smoking on disease outcome in rheumatoid arthritis. Curr Opin Rheumatol 2002;14:93-7.

11. Verstappen SM, McCoy MJ, Roberts C, Dale NE, Hassell AB, Symmons DP. Beneficial effects of a 3-week course of intramuscular glucocorticoid injections in patients with very early inflammatory polyarthritis: results of the STIVEA trial. Ann Rheum Dis 2010;69:503-9.

12. Kirwan JR, Reeback JS. Stanford Health Assessment Questionnaire modified to assess disability in British patients with rheumatoid arthritis. Br J Rheumatol 1986;25:206-9.

13. EuroQol - a new facility for the measurement of health-related quality of life. The EuroQol Group. Health Policy 1990;16:199-208.

14. Jenkinson C, Coulter A, Wright L. Short-form 36 (SF-36) health survey questionnaire: normative data for adults of working age. BMJ 1993;306:1437-40.

15. Talamo J, Frater A, Gallivan S, Young A. Use of the short-form 36 (SF-36) for health status measurement in rheumatoid arthritis. Br J Rheumatol 1997;36:463-9.

16. van der Woude D, Young A, Jayakumar K, Mertens BJ, Toes RE, van der Heijde D, et al. Prevalence of and predictive factors for sustained disease-modifying antirheumatic drug-free remission in rheumatoid arthritis: results from two large early arthritis cohorts. Arthritis Rheum 2009;60:2262-71.

17. Stolt P, Bengtsson C, Nordmark B, Lindblad S, Lundberg I, Klareskog L, et al. Quantification of the influence of cigarette smoking on rheumatoid arthritis: results from a population based case-control study, using incident cases. Ann Rheum Dis 2003;62:835-41.

18. Heliovaara M, Aho K, Aromaa A, Knekt P, Reunanen A. Smoking and risk of rheumatoid arthritis. J Rheumatol 1993;20:1830-5. 